\title{
REVIEWS.
}

\section{THE HAIR AND SCALP.}

By Agnes Savill, London.

Edward Arnold and Co. $1935 . \quad$ pp. 288. Price 12/6 net.

Within the covers of this book of nearly 300 pages is contained a mass of useful information about the hair and scalp in health and disease. The authoress is to be complimented upon the care which she has taken in collecting her facts, and the wise and thoughtful selection of the material embodied in the letterpress. Commencing with a full description of the structure and physiology of the hair, with a special chapter written by Mr. W. T. Astbury on its molecular structure and elastic properties, the writer goes on to describe the disorders and diseases which affect the hair and scalp in detail. This is set out in chapters under such headings as diffuse hairfall, itching of the scalp, scaly conditions of the scalp, vesicular and bullous conditions and erythematous eruptions. These chapters are written in an interesting and lucid fashion and bring together the pathological changes affecting the hair and scalp, which are of necessity widely distributed in the ordinary textbooks on skin diseases.

In addition there is a series of chapters which seem to us to give this book its special character and value, namely, the chapters on grey hair, the care of the hair and scalp, hair dyes and hypertrichosis. These chapters are admirable and contain information and observations which are as a rule absent from textbooks on dermatology, written by a close observer who has made a lifelong study of the minor defects of the skin and scalp, and of the psychological effect of disfigurements of the skin, which, though at first sight may seem trivial, frequently loom with such importance in the minds of those that suffer from them as to undermine the general health and even the mental stability.

Among these observations it is a relief to find a contradiction to the timehonoured fallacy so firmly fixed in the public mind that greasy applications and shaving have a stimulating effect on the rate of growth of the hair, and the statement that there is no scientific proof that singeing of the hair has any beneficial effect and that it may be actually harmful by drying the hair further up the hair shaft.

The correct methods of brushing and combing the hair are described in detail and the danger of the promiscuous use without proper cleansing of brushes and combs, at home or by the barber, is emphasized. A short list of useful formulæ for the treatment of pityriasis, psoriasis, greasiness of the scalp and hair, alopecia areata, etc., is appended.

The book is adequately illustrated and well printed, is a welcome addition to dermatological literature and may be read with profit not only by those interested in skin diseases but by every medical practitioner.

\section{THE EARLY DIAGNOSIS OF MALIGNANT DISEASE.}

By Geoffrey Keynes, M.A., M.D., F.R.C.S.Eng. John Bale, Sons \& Danielsson Ltd. 1935. Price 2/6d.

This is an admirable little book, which should be in the hands of every general practitioner. If the precepts which it contains were carried out they would do more than anything else to reduce the number of cases of cancer which are brought for treatment too late for the patient to have a good, reasonable chance of cure.

Cancer of all the different organs of the body is considered separately, and those symptoms which lead to suspicion of the possibility of a tumour are carefully related. Far too many of the symptoms of cancer in various parts of the body now given in textbooks are those of the late stages of the disease when diagnosis is no longer important, whereas the very early symptoms are too often neglected. This book tends to fill a real want in giving those symptoms and signs which occur in the very earliest stages of malignant disease, which should make the doctor suspicious, and encourage him to use modern methods to try and confirm or negative his suspicions. 
There are particularly good chapters on the early signs of cancer of the breast, cancer of the stomach, and on the X-ray diagnosis between cancer of the stomach and simple ulcer. The early signs which give rise to carcinoma of the colon are very carefully considered and the means by which the diagnosis may be confirmed. It is also pointed out that most cases of carcinoma of the rectum could be easily detected in the very early stage were the doctor always to make a rectal examination directly he sees a patient bleeding from the rectum, or with any other signs which might be due to a carcinoma. The chapter on early signs of carcinoma of the prostate is quite excellent, as is also that on the thyroid gland. The chief signs which should make one suspicious of the onset of malignant disease in a previously existing adenoma of the thyroid are carefully pointed out and should be borne in mind by everybody who has to deal with such cases.

The book is very clearly written and gives an extremely fair summary of a very difficult subject.

\section{AIDS TO MEDICINE.}

(Fifth Edition.)

By T. L. Livingstone, M.D. Baillière, Tindall \& Cox. 1935. Price 5/-.

Although one fears that books of this nature on occasion form the sole medical literature of some students, there is no doubt that they form a useful purpose when properly used. As a pocket-book of reference for the student to carry about on his ward rounds or during his frequent viva voce examinations by a colleague it is of very definite value so long as the information contained is reliable. From a perusal of Dr. Livingstone's "Aids to Medicine" we have no hesitation in recommending it for this purpose.

\section{MEDICAL \& D.P.H. EXAMIN- ATION PAPERS (1932-r935).}

E. \& S. Livingstone. 1935 . 3/6d.

This volume is a collection of the examination papers set during the years 1932-35 in the various subjects comprising the course for the Degree of M.B., the Diploma in Public Health, the Diploma in Fsychiatry, the Diploma in Radiology, the Diploma in Tropical Medicine and Hygiene of the University of Edinburgh, for the Licence in Medicine and Surgery and the Diploma in Public Health of the Conjoint Board and for the Membership of the Royal College of Physicians, Edinburgh and should be of service to candidates preparing for the various examinations.

\section{KÖHLER'S RÖNGENOLOGY.}

Translated by A. Turnbull. B.Sc., M.B. Pp. xvi+632, with over 400 illustrations. Size $7 \times 10$. Publishers, Baillière, Tindall \& Cox. Price 50s.

Radiologists will rejoice that " Köhler " has been re-published in English. In the original German, the book has reached its sixth edition, and it has also been translated into French, Hungarian, Italian and Polish. Köhler was the first to describe the disease of the tarsal scaphoid, and that of the head of the second metatarsal bone, which have since been associated with his name. For his work and publications he has been honoured by the Radiological Societies of Britain, Austria, Belgium, Germany, Mexico, Sweden and Spain.

The book represents the life experience of one who remembers as a student, the announcement of Roentgen's discovery and all the disbelief it aroused, and who even in 1899 was taking radiographs of joints and limbs which are not much improved upon to-day, and that with a tube costing only about eighteen shillings! Thus he has seen much, and his observation must be of use to all of us.

The whole of the diagnostic field is covered in so far as direct radiography can be employed, and in addition barium meal and enema examinations and cholecystography are included. Other methods such as pyelography, aortography, bronchography, kymography, sialography and so on, are not included.

His book deals not with gross cases of advanced disease, but with the normal and 